\title{
Inherited thrombophilia is significantly associated with severe preeclampsia
}

\author{
ROXANA ELENA BOHILTEA ${ }^{1,2}$, MONICA MIHAELA CIRSTOIU ${ }^{1,2}$, NATALIA TURCAN ${ }^{2,3}$, \\ ANCA PANTEA STOIAN ${ }^{4}$, CORINA-AURELIA ZUGRAVU ${ }^{5}$, OCTAVIAN MUNTEANU $^{2,6}$, \\ LUCIANA VALENTINA ARSENE ${ }^{2,3}$, BODEAN OANA ${ }^{2}$, ADRIAN NEACSU $^{1}$ and FLORENTINA FURTUNESCU ${ }^{7}$ \\ ${ }^{1}$ Department of Obstetrics and Gynecology, 'Carol Davila' University of Medicine and Pharmacy, 020021 Bucharest; \\ ${ }^{2}$ Department of Obstetrics and Gynecology, University Emergency Hospital Bucharest, 050098 Bucharest; \\ ${ }^{3}$ Department of Obstetrics and Gynecology, 'Carol Davila' University of Medicine and Pharmacy, \\ Doctoral School, 020021 Bucharest; ${ }^{4}$ Department of Diabetes, Nutrition and Metabolic Diseases, \\ 'Carol Davila' University of Medicine and Pharmacy, 020475 Bucharest; 5 Department of Food Hygiene and Nutrition, \\ 'Carol Davila' University of Medicine and Pharmacy, 050463 Bucharest; ${ }^{6}$ Department of Anatomy, \\ 'Carol Davila' University of Medicine and Pharmacy, 020021 Bucharest; ${ }^{7}$ Department of Public Health and Management, \\ Faculty of Medicine, 'Carol Davila' University of Medicine and Pharmacy, 050463 Bucharest, Romania
}

Received September 28, 2020; Accepted October 26, 2020

DOI: $10.3892 /$ etm.2021.9691

\begin{abstract}
Methods to prevent the development of pathologies due to placental dysfunctions, such as gestational hypertension and preeclampsia, are the main approaches for obtaining the best maternal and fetal antepartum and postpartum prognosis. During 5 years of study (January, 2015 to December, 2019), the cases of pregnancy and puerperium complicated with pathology due to placental dysfunction were analyzed. The main objective was to determine the magnitude of the impact of thrombophilia on the development of an entity of gestational hypertension disorder. We compared the impact of thrombophilia and its associated complications in patients with gestational hypertension with moderate and severe preeclampsia. Thus, we found obesity, thrombophilia, and underlying cardiac pathology to be significant risk factors for severe preeclampsia. Regarding the comparative analysis of the risk factors and complications associated with patients with mild preeclampsia compared with those with severe preeclampsia, the presence in severe preeclampsia of thrombophilia, endocrine, liver, and cardiac
\end{abstract}

Correspondence to: Professor Roxana Elena Bohiltea, Department of Obstetrics and Gynecology, 'Carol Davila' University of Medicine and Pharmacy, Dionisie Lupu 37, 020021 Bucharest, Romania

E-mail: r.bohiltea@yahoo.com

Associate Professor Corina-Aurelia Zugravu, Department of Food Hygiene and Nutrition, 'Carol Davila' University of Medicine and Pharmacy, Doctor Leonte Anastasievici 1-3, 050463 Bucharest, Romania

E-mail: corina.zugravu@insp.gov.ro; dr_corinazugravu@yahoo.com

Key words: preeclampsia, thrombophilia, pregnancy, obesity, oligohydramnios pathology was higher and, a higher rate of complications was observed; complications included fetal death, intrauterine growth restriction (IUGR), prematurity, fetal arrhythmia with acute fetal distress, HELLP syndrome, and placental abruption. Thrombophilia has a significant effect on the development of severe preeclampsia, and oligohydramnios as specific complication of mild preeclampsia. Factors indicating an increased risk of progression from mild preeclampsia to severe preeclampsia are in addition to inherited thrombophilia the underlying pathologies, namely cardiac, hepatic, and endocrine factors.

\section{Introduction}

The pathologies included in the spectrum of hypertensive diseases in pregnancy have long been studied, and studies will certainly continue in this direction as long as these conditions maintain a significant incidence as well as their associated morbidity and mortality rates (1). Methods to prevent the development of pathologies due to placental dysfunctions, such as gestational hypertension and preeclampsia, are the main approaches for obtaining the best maternal and fetal antepartum and postpartum prognosis (2). The risk factors include previous preeclampsia, chronic renal disease, chronic hypertension, diabetes mellitus, systemic lupus erythematosus or antiphospholipid syndrome, first pregnancy, maternal age $>35$ years, body mass index $>35 \mathrm{~kg} / \mathrm{m}^{2}$, inter-pregnancy interval $>10$ years, family history of preeclampsia, which have demonstrated their impact according to numerous studies and have been adopted by The National Institute for Health and Care Excellence guidelines 2010 and by the American College of Obstetricians and Gynecologists guidelines 2020 as screening tools (3-10). When corroborated with laboratory and imaging tests $(11,12)$, patients with a high risk of developing preeclampsia can be selected and they can be offered low-dose aspirin therapy starting at 
the end of the first trimester and an appropriate pregnancy management. The link between inherited thrombophilia and preeclampsia continues to remain disputed; data from some prospective cohort studies indicate that major thrombophilic factors are not associated with preeclampsia and screening is not useful for predicting the high risk of developing the disease $(13,14)$, but other studies suggest the opposite (15-18). However, preeclampsia occurs in a significant number of cases in nulliparous patients, with an apparent health status that does not present any obvious risk factor or relevant maternal-fetal pathology (19-24). The prognosis of complicated cases with gestational hypertension is usually good, even significantly better than that of complicated cases with preeclampsia. About half of the cases with gestational hypertension will progress to preeclampsia, and the risk of decompensating is inversely proportional to the gestational age at gestational hypertension onset; thrombocytopenia and persistently impaired liver function underline the severity of preeclampsia (25). The earlier the gestational hypertension occurs in pregnancy, the greater is the risk of progression to preeclampsia. Preeclampsia is associated with a poor maternal and fetal prognosis in terms of perinatal mortality especially if it imposes iatrogenic prematurity (26-28).

\section{Patients and methods}

Patients and groups. During the 5 years (2015-2019) of study, the cases of pregnancy and puerperium complicated with pathology due to placental dysfunction were analyzed by collecting data from the Medical Statistics Department of the University Emergency Hospital Bucharest. The initial case groups included: Control group 1 formed by selecting 200 randomly healthy pregnant women, matched by age and sociodemographics, with no hypertension diagnosed pre-pregnancy or during pregnancy, from the large sample of women presented at our clinic for usual pregnancy controls during the period of the current study; group 2, including patients with preexisting pregnancy hypertension (67 cases); group 3, patients with gestational hypertension (240 cases); group 4, patients with moderate preeclampsia (319 cases); group 5, patients with severe preeclampsia (130 cases); group 6, patients with eclampsia (16 cases). Due to insufficient data about group 6, it was excluded from the study. Group 2 had a similar profile of complications and pathologic association as group 1 (general population), with no statistically significant differences, so in the present statistical analysis it was not included.

Analysis of the proportion of the impact of inherited thrombophilia on the development of gestational hypertension or preeclampsia. The main objective was to analyze the proportion of the impact of inherited thrombophilia such as mutations in factor $\mathrm{V}$ Leiden rs6025, heterozygous or homozygous and haplotype factor R2, A4070G, rs1800595 heterozygous or homozygous; factor II mutation, prothrombin gene G20210A (rs1799963) and its genotype; antithrombin deficiency (mutations 11T3 AT); the factor XIII V34L mutation (G103T, rs5985) and its genotype; plasminogen activator inhibitor 1 (PAI-1) gene polymorphism; methylenetetrahydrofolate reductase (MTHFR) A1298C and C677T and mutations in the endothelial protein $C$ receptor $(E P C R)$ gene $G 4600 A$ (rs867186, S219G) and C4678G (rs9574) in the development of a form of gestational hypertension or preeclampsia.

Hypertensive group criteria. Each patient was included in one group according to the last criteria included in the definition of hypertensive disorders of pregnancy. Respectively, chronic hypertension was defined as hypertension that was present before pregnancy or was present on at least two occasions before the accomplishment of 20 weeks of gestation or persisted longer than 12 weeks' postpartum; gestational hypertension was defined as the new onset of hypertension with systolic blood pressure $\geq 140 \mathrm{mmHg}$ and/or diastolic blood pressure $\geq 90 \mathrm{mmHg}$ after 20 weeks of gestation in the absence of proteinuria or new signs of end-organ dysfunction (29). Preeclampsia was defined as the new-onset of hypertension that is accompanied by specific signs or symptoms of significant end-organ dysfunction severe features of the preeclampsia spectrum being indicated by high values of hypertension (systolic blood pressure $\geq 160 \mathrm{mmHg}$ and/or diastolic blood pressure $\geq 110 \mathrm{mmHg}$ ) also with specific signs or symptoms of severe end-organ dysfunction.

Statistical analysis. In the context in which the data was not a Gaussian distribution, nonparametric tests, such as the Mann-Whitney U test, were respectively applied between the different study groups and the risk factors, and subsequently, the complications encountered were analyzed. In order to evaluate the association of risk factors with each of the pathologies related to hypertension in pregnancy, multinominal and binary logistic regression models were performed using the pathology categories as the dependent variables and the different risk factors. The significance for the pathology groups studied in the nonparametric tests was applied in the first stage. SPSS 12.0 (IBM, Corp.) was used for statistical analysis, and the statistical significance threshold was set at $\mathrm{P}<0.05$.

\section{Results}

Descriptives regarding the groups included in the statistical analysis in the present paper are presented in Table I. In a first step, we applied Mann-Whitney U tests, first comparing complications in moderate and severe preeclampsia, with their presence in pregnancy-induced hypertension (Table II), and then compared their presence in severe vs. moderate preeclampsia cases (Table III). The analysis showed that there was a statistically significant association of the severity of preeclampsia (severe preeclampsia cases vs. pregnancy-induced hypertension cases) with the presence of thrombophilia. Inherited thrombophilia had a increased frequency in groups 4 and 5 of mild and severe preeclampsia. Our results showed also that the presence of oligohydramnios was linked with the presence of preeclampsia. By dividing into severity class, oligohydramnios appeared to be statistically significantly associated with mild preeclampsia, compared with pregnancy hypertension, and also with severe preeclampsia. Complications such as intrauterine growth restriction (IUGR), prematurity, fetal arrhythmia with acute fetal distress, infection and placental abruption were significantly linked with severe preeclampsia, compared with pregnancy-induced hypertension (Table II) 
Table I. Descriptives of groups 3, 4 and 5.

\begin{tabular}{lccc}
\hline & $\begin{array}{c}\text { Group 3 Pregnancy-induced } \\
\text { hypertension }(\mathrm{n}=240) \mathrm{n}(\%)\end{array}$ & $\begin{array}{c}\text { Group 4 Moderate } \\
\text { preeclampsia }(\mathrm{n}=319) \mathrm{n}(\%)\end{array}$ & $\begin{array}{c}\text { Group 5 Severe } \\
\text { preeclampsia }(\mathrm{n}=130) \mathrm{n}(\%)\end{array}$ \\
\hline Thrombophilia & $25(10.42)$ & $47(14.73)$ & $30(23)$ \\
IUGR & $16(6.67)$ & $42(13.17)$ & $33(25.4)$ \\
Oligohydramnios & $13(5.42)$ & $67(21)$ & $20(15.4)$ \\
Prematurity & $15(6.25)$ & $18(5.64)$ & $29(22.3)$ \\
Fetal arrhythmia & $6(2.5)$ & $11(3.45)$ & $13(10)$ \\
HELLP syndrome & $2(0.83)$ & $2(0.63)$ & $14(10.8)$ \\
Infections & $38(15.8)$ & $36(11.3)$ & $22(17)$ \\
Placental abruption & $18(7.5)$ & $20(6.3)$ & $20(15.4)$ \\
Cardiac pathology & $2(0.83)$ & $1(0.3)$ & $13(10)$ \\
Liver pathology & $0(0.0)$ & $3(1)$ & $5(3.85)$ \\
Endocrine pathology & $8(3.33)$ & $7(2.2)$ & $8(6.15)$
\end{tabular}

IUGR, intrauterine growth restriction.

Table II. Inherited thrombophilia and the main associated complications encountered in the pregnancy-induced hypertension patients compared with mild preeclampsia and severe preeclampsia cases.

\begin{tabular}{|c|c|c|c|c|c|c|c|c|}
\hline & \multicolumn{4}{|c|}{$\begin{array}{l}\text { Mild preeclampsia }(n=319) \text { vs. } \\
\text { pregnancy-induced hypertension }(n=240)\end{array}$} & \multicolumn{4}{|c|}{$\begin{array}{c}\text { Severe preeclampsia }(n=130) \text { vs. } \\
\text { pregnancy-induced hypertension }(n=240)\end{array}$} \\
\hline & $\mathrm{U}$ & $\mathrm{z}$ & P-value & $\mathrm{r}$ & $\mathrm{U}$ & $\mathrm{z}$ & $\mathrm{P}$-value & $\mathrm{r}$ \\
\hline Thrombophilia & - & & & & 11611 & -2.6 & 0.01 & -0.11 \\
\hline IUGR & - & - & - & - & 10728 & -4.4 & $<0.001$ & -0.19 \\
\hline Oligohydramnios & 20045 & -9.1 & $<0.001$ & -0.4 & 11847 & -2.7 & 0.007 & -0.12 \\
\hline Prematurity & - & - & - & - & 11067 & -4 & $<0.001$ & -0.18 \\
\hline Fetal arrhythmia & - & - & - & - & 12103 & -2.7 & $<0.001$ & -0.12 \\
\hline HELLP syndrome & - & - & - & - & 11744 & -4 & $<0.001$ & -0.18 \\
\hline Infections & 28599 & -3.3 & $<0.001$ & -0.14 & - & - & - & - \\
\hline Placental abruption & - & - & - & - & 12184 & -3.3 & $<0.001$ & -0.14 \\
\hline
\end{tabular}

Only significant associations are presented $(\mathrm{P}<0.05) . \mathrm{r}$ represents the size of the effect of the respective variable; that is, the greater the value of $r$ the more important the influence of the variable. The test statistic for the Mann Whitney U Test is denoted as $\mathbf{U}$. IUGR, intrauterine growth restriction.

In a previous study, we found obesity and underlying cardiac pathology to be significant risk factors for severe preeclampsia (30). In the present study we confirmed that there was a significant difference in the presence of complications such as IUGR, oligohydramnios, prematurity, fetal arrhythmia, acute fetal distress, HELLP syndrome, and placental abruption for group 5 patients with severe preeclampsia, compared with the group with pregnancy-induced hypertension (Table II). Even though the impact of complications falls within the sphere of small values, the effects are more substantial [need for NICU (neonatal intensive care unit), prematurity, and HELLP syndrome].

Regarding the comparative analysis of the risk factors and complication associated with patients with mild preeclampsia vs. those with severe preeclampsia (Table III), the results revealed that there was a significant association of severe preeclampsia with thrombophilia, endocrine, liver, and cardiac pathology, compared with the same complications in mild preeclampsia.

Thrombophilia is the next significant risk factor for severe preeclampsia, and an associated underlying pathology (endocrine, hepatic, or cardiac) has a significant impact only on severe preeclampsia, compared with mild one (Tables II and III).

In the context in which thrombophilia was found to be a significant risk factor by comparative nonparametric tests between the studied groups, we carried out an analysis in order to establish the severity index. From the above results, it can be seen that thrombophilia is a statistically significant severity indicator; its impact is important not only in the general population, but also between the case groups. The impact increases as the severity of the case increases. Of the 
Table III. Risk factors associated with inherited thrombophilia represented comparatively of the patients with mild preeclampsia $(n=319)$ and those with severe preeclampsia $(n=130)$.

\begin{tabular}{lcccc}
\hline & \multicolumn{4}{c}{$\begin{array}{c}\text { Severe preeclampsia compared to } \\
\text { mild preeclampsia }\end{array}$} \\
\cline { 2 - 5 } Risk factors & $\mathrm{U}$ & $\mathrm{z}$ & P-value & $\mathrm{r}$ \\
\hline Thrombophilia & 18772 & -2.15 & 0.03 & -0.1 \\
Cardiac pathology & 18508 & -5.36 & 0.00 & -0.25 \\
Liver pathology & 19909.5 & -2.11 & 0.03 & -0.1 \\
Endocrine pathology & 19690.5 & -2.12 & 0.03 & -0.1 \\
\hline
\end{tabular}

Only significant associations are presented $(\mathrm{P}<0.05)$. $\mathrm{r}$ represents the size of the effect of the respective variable, that is, the greater the value of $r$ the more important the influence of the variable. The test statistic for the Mann Whitney U Test is denoted as U.

risk factors analyzed, thrombophilia seemed to be strongly associated with the severity of the case, the closest connection is with severe preeclampsia. It has significant lower impact as a risk factor for gestational hypertension or mild preeclampsia as demonstrated trough multinomial regression models that identify potential predictors. The models included the study group category as dependent variables, and as independent variables, the statistically significant risk factors identified in the previous stage oriented mainly to thrombophilia.

A logistic binary regression model, with the category as dependent variable, was developed for the purpose of the analysis of group 4 in relation to group 5 regarding the predictive value of thrombophilia, considered as independent variable. The model has a Chi-square $(3)=15.9, \mathrm{P}<0.05$, and explains $26.4 \%$ of patients' probability of developing severe preeclampsia, from mild preeclampsia (Nagelkerke $=0.264)$. There are no large correlation factors between the independent variables; thus, collinearity can be excluded. What could be observed in the binary regression model was that thrombophilia, as a risk factor, loses its predictive value in case evolution. We can consider it as a negative predictor of pregnancy hypertension and preeclampsia just in relation with the general population, driving the necessity of a closer follow-up of the thrombophilic patient.

\section{Discussion}

The relationship between thrombophilic mutations and preeclampsia is an intensely studied and debated topic, and the results and conclusions are divided. Thrombophilia increases the risk of patients with pregnancy-induced hypertension to develop severe preeclampsia. This association was first reported decades ago (31). Due to the influence of this report, thrombophilia screening was indicated for patients with previous severe preeclampsia episodes and appropriate treatment in subsequent pregnancies. Succeeding studies have confirmed or rejected this report $(13,14,32)$. The differences in the conclusions are largely due to the lack of prospective studies with a consistent design for the assessment of the risk of preeclampsia in the general, asymptomatic, and carrying population of thrombophilic mutations, but in return are based on results from retrospective studies with heterogeneous groups (33-35). Most studies performed on the relationship between thrombophilia and preeclampsia are based on the results of term pregnancies as a control group and complicated pregnancies with preeclampsia treated in tertiary centers as a case group; thus, the results are due to a bias that overestimates the impact of thrombophilia in the group case and underestimates it in the control group. A common result from most studies is the link between thrombophilia and severe preeclampsia to the detriment of the mild one $(36,37)$, a result obtained in the study group as well.

The fact that oligohydramnios is a sign of chronic fetal distress due to utero-placental insufficiency has long been studied and has long been a consensus. Placental dysfunction with chronic hypoxic status results in the redistribution of circulation to the vital organs; therefore, the non-essential organs such as the kidneys receive inadequate circulatory flow with low fetal diuresis and decreased amniotic fluid levels. Oligohydramnios may exist as a unique sign of fetal distress in preeclampsia in the presence of a non-stress and IUGR test (38-41). The relationship between oligohydramnios and the severity of the associated hypertensive condition has been investigated in numerous studies, which have shown that the oligohydramnios sensitivity as a negative prognostic factor is low with a percentage of $45 \%$ (42).

The statistically significant relationship of oligohydramnios as a complication of mild preeclampsia is justified by the fact that mild preeclampsia offers an expectation management window, with continuous monitoring and does not represent a firm indication of termination of the pregnancy, except in the presence of other signs of fetal decompensation $(40,41)$. In addition, we found a significantly increased incidence of oligohydramnios among severe preeclampsia patients compared to patients with pregnancy-induced hypertension, IUGR, prematurity, and acute fetal distress, HELLP syndrome and placental abruption. Each of the complications listed increases in proportion with the increasing severity of the pathology. Fetal decompensation shows acute fetal distress that usually occurs when pregnancy-induced hypertension is destabilized by HELLP syndrome or significantly increased blood pressure, a major placental abruption risk factor (43).

Factors indicating an increased risk of progression from mild preeclampsia to severe preeclampsia are in addition to thrombophilia, underlying pathologies such as cardiac, hepatic, and endocrine, a circumstance justified by the fact that an already affected system will be much more easily affected by possible complications in pregnancy. Thus, preeclampsia, which is characterized by generalized endothelial dysfunction with implicated vasoconstriction, will have an aggravating impact on impaired cardiac function.

Regarding the increased risk of HELLP syndrome, its pathophysiology is not fully elucidated, but at its base is endothelial dysfunction (44). Hepatic function is affected by fibrin storage at the liver level, resulting in sinusoidal capillary obstruction leading to vascular congestion and increased intrahepatic pressure (45). Placental derived factors, such as CD95L, are hepatotoxic, leading to hepatocyte apoptosis and hepatic necrosis by increasing TNFa (46). Microangiopathies, 
characteristic of preeclampsia, are present in the liver and further affect liver function. These mechanisms that negatively impact liver function, which are superimposed on an already altered liver function, have an increased exponential impact.

Taking into account that the placenta of preeclamptic women displays characteristic features of uteroplacental ischemia, the use of prophylactic low molecular weight heparin (LMWH) in selected high-risk women with thrombophilic genetic variants has been suggested to prevent recurrent pregnancy complications (47-52). However, available data, although limited, do not support this practice (53), further investigation is warranted, but actual guidelines of prevention of thromboembolic disease in pregnancy sustain administration of LMWH in the presence of high-risk factors: Antithrombin deficiency, homozygotes of factor V Leiden, homozygotes of prothrombin gene mutation, or compound heterozygote factor $\mathrm{V}$ Leiden and prothrombin gene mutation (54-59).

Regression models were developed to confirm the predictive values of the risk factors analyzed. These results confirm the link between thrombophilia and severe preeclampsia, as demonstrated by other studies (60).

In conclusion, thrombophilia has a significant effect on the development of severe preeclampsia, and oligohydramnios is a specific complication of mild preeclampsia. A clear determination of the predisposition towards a form of hypertension in pregnancy and with a management adapted to each case is mandatory in order to prevent the unfavorable maternal-fetal prognosis related to these pathologies. Thrombophilia significantly affects the evolution of hypertensive disease in pregnancy, but is not involved in their pathophysiological mechanism, the effect of thrombophilia being superimposed on the pathophysiological changes characteristic of preeclampsia.

\section{Acknowledgements}

Not applicable.

\section{Funding}

No funding was received.

\section{Availability of data and materials}

The datasets used and/or analyzed during the current study are available from the corresponding author upon reasonable request.

\section{Authors' contributions}

REB, NT, and MMC collected, analyzed and interpreted the patient data regarding the impact of thrombophilia on the evolution of a hypertensive pathology that complicates the pregnancy. REB, CAZ and FF had substantial contribution to the conception of the work and interpretation of data and were major contributors in writing the manuscript. AN, APS, LVA, $\mathrm{BO}$ and $\mathrm{OM}$ drafted the manuscript, contributing to conception of the research, further drafts and comments. CAZ and FF performed statistical analysis and study description. All authors read and approved the final manuscript.

\section{Ethics approval and consent to participate}

The data collected retrospectively did not contain personal information and only the Ethics Committee agreement of the University Emergency Hospital of Bucharest was required and obtained without the need of informed consent or the consent of the patient/legal representative in the case of minors.

\section{Patient consent for publication}

Not applicable.

\section{Competing interests}

The authors declare that they have no competing interests.

\section{References}

1. Report of the national high blood pressure education program working group on high blood pressure in pregnancy. Am J Obstet Gynecol 183 (Suppl 1): S1-S22, 2000.

2. Sibai BM and Stella CL: Diagnosis and management of atypical preeclampsia-eclampsia. Am J Obstet Gynecol 200: 481, 2009.

3. American College of Obstetricians and Gynecologists' Committee on Practice Bulletins-Obstetrics. Gestational hypertension and preeclampsia: ACOG practice Bulletin, Number 222. Obstet Gynecol 135: e237-e260, 2020.

4. https://www.nice.org.uk/guidance/qs35/chapter/quality-statement-2antenatal-assessment-of-pre-eclampsia-risk\#what-the-qualitystatement-means-for-service-providers-healthcare-practitionersand-commissioners-2. Accessed November 2, 2020.

5. Myatt L, Clifton RG, Roberts JM, Spong CY, Hauth JC, Varner MW, Thorp JM Jr, Mercer BM, Peaceman AM, Ramin SM, et al: First-Trimester prediction of preeclampsia in nulliparous women at low risk. Eunice kennedy shriver national institute of child health and human development (NICHD) maternal-fetal medicine units (MFMU) network. Obstet Gynecol 119: 1234-1242, 2012.

6. Bartsch E, Medcalf KE, Park AL and Ray JG: High risk of pre-eclampsia identification group: Clinical risk factors for pre-eclampsia determined in early pregnancy: Systematic review and meta-analysis of large cohort studies. BMJ 353: i1753, 2016.

7. Lee RM, Brown MA, Branch DW, Ward K and Silver RM: Anticardiolipin and anti-B2 glycoprotein-I antibodies in preeclampsia. Obstet Gynecol 102: 294-300, 2003.

8. Opatrny L, David M, Kahn SR, Shrier I and Rey E: Association between antiphospholipid antibodies and recurrent fetal loss in women without autoimmune disease: A metaanalysis. J Rheumatol 33: 2214-2221, 2006.

9. Bohîlțea RE, Turcan N, Ionescu CA, Mehedințu C, Nastasia S, Toader O, Munteanu $\mathrm{O}$ and Cîrstoiu MM: Ultrasound diagnosis of abnormal adherent placenta-literature review. Filodiritto Editore-Proceedings. 5th Romanian Congress of the Romanian Society of Ultrasound in Obstetrics and Gynecolog: 113-119, 2017.

10. Devoe LD, Gardner P, Dear C and Castillo RA: The diagnostic values of concurrent nonstress testing, amniotic fluid measurement and doppler velocimetry in screening a high-risk population. Am J Obstet Gynecol 163: 1040-1048, 1990.

11. Agrawal S, Cerdeira AS, Redman C and Vatish M: Meta-analysis and systematic review to assess the role of soluble FMS-like tyrosine kinase-1 and placenta growth factor ratio in prediction of preeclampsia: The SaPPPhirE study. Hypertension 71: 306-316, 2018.

12. Kleinrouweler CE, Bossuyt PM, Thilaganathan B, Vollebregt KC, Ramírez JA, Ohkuchi A, Deurloo KL, Macleod M, Diab AE, Wolf $\mathrm{H}$, et al: Value of adding second-trimester uterine artery doppler to patient characteristics in identification of nulliparous women at increased risk for pre-eclampsia: An individual patient data meta-analysis. Ultrasound Obstet Gynecol 42: 257-267, 2013. 
13. Dizon-Townson D, Miller C, Sibai B, Spong CY, Thom E, Wendel G Jr, Wenstrom K, Samuels P, Cotroneo MA, Moawad A, et al: National institute of child health and human development maternal-fetal medicine units network. The relationship of the factor V Leiden mutation and pregnancy outcomes for mother and fetus. Obstet Gynecol 106: 517-524, 2005.

14. Silver RM,Zhao Y, Spong CY, Sibai B, Wendel G Jr, Wenstrom K, Samuels P, Caritis SN, Sorokin Y, Miodovnik M, et al: Eunice kennedy shriver national institute of child health and human development maternal-fetal medicine units (NICHD MFMU) network. Prothrombin gene G20210A mutation and obstetric complications. Obstet Gynecol 115: 14-20, 2010.

15. Mello G, Parretti E, Marozio L, Pizzi C, Lojacono A, Frusca T, Tondi F, Borri P, Scarselli G and Sibai BM: Thrombophilia is significantly associated with severe preeclampsia. Results of a large scale, care-controlled study. Hypertension 46: 1270-1274, 2005.

16. Voicu DI, Munteanu O, Gherghiceanu F, Arsene LV, Bohillea RE, Gradinaru DM and Cirstoiu MM: Maternal inherited thrombophilia and pregnancy outcomes. Exp Ther Med 20: 2411-2414, 2020.

17. Păulet FP, Turcan N, Gherghiceanu F, BohPlţea RE, Nemescu D and CPrstoiu MM: Prognosis of autoimmune thyroid disease associated with hereditary thrombophilia during pregnancy. Exp Ther Med 20: 2429-2433, 2020.

18. Paidas MJ, Ku DH and Arkel YS: Screening and management of inherited thrombophilias in the setting of adverse pregnancy outcome. Clin Perinatol 31: 783-805, 2004.

19. Sheikh M, Zoham MH, Hantoushzadeh S, Shariat M, Dalili H and Amini E: Umbilical blood gas analysis in preeclamptic versus healthy pregnancies with preterm birth. J Matern Neonatal Med 29: 1-6, 2015.

20. Bohîlțea RE, Zugravu CA, Neacsu A, Navolan D, Berceanu C, Nemescu D, Bodean O, Turcan N, Baros A and Cîrstoiu MM: The prevalence of vitamin D deficiency and its obstetrical effects. A prospective study on Romanian patients. Rev Chim 70: 1228-1233, 2019.

21. Tiglis M, Neagu TP, Elfara M, Diaconu CC, Bratu OG, Vacaroiu IA and Grintescu IM: Nefopam and its role in modulating acute and chronic pain. Rev Chim 69: 2877-2880, 2018.

22. Bohîlţea RE, Tufan CF, Cîrstoiu MM,Dumitru AV, Georgescu TA Sajin M, Bodean OM, Munteanu O, Brătilă E, Ofiteru AM and Berceanu C: Body stalk anomaly in a monochorionic-diamniotic twin pregnancy-case report and review of the literature. Rom J Morphol Embryol 58: 1453-1460, 2017.

23. Nastas A, Stanculescu R, Mehedințu C, Berceanu C, Comandasu D, Cîrstoiu M, Bohîltea R, Vladareanu S, Patrascoiu S, Nastas AL and Bratilă E: The management of grade II/III hydronephrosis during pregnancy. Proceedings of Filodiritto Editore-Proceedings, The 13th National Congress of Urogynecology (UROGYN 2016): 195-199, 2016.

24. Munteanu O, Cîrstoiu MM, Filipoiu FM, Bohîltea RE, Brătilă E, Bulescu IA and Berceanu C: Morphological and ultrasonographic study of fetuses with cervical hygroma. A case series. Rom J Morphol Embriol 57: 1421-1427, 2016.

25. Homer CS, Brown MA, Mangos G and Davis GK: Non-Proteinuric pre-eclampsia: A novel risk indicator in women with gestational hypertension. J Hypertens 26: 295-302, 2008.

26. Bohîlțea R, Furtunescu F, Turcan N, Navolan D, Ducu I and Cîrstoiu M: Prematurity and intrauterine growth restriction: Comparative analysis of incidence and short term complication. Proceedings of SOGR 2018. The 17th National Congress of the Romanian Society of Obstetrics and Gynecology 2018: 708-712, 2019.

27. Turcan N, Bohiltea RE, Ionita-Radu F, Furtunescu F, Navolan D, Berceanu C, Nemescu D and Cirstoiu MM: Unfavorable influence of prematurity on the neonatal prognostic of small for gestational age fetuses. Exp Ther Med 20: 2415-2422, 2020.

28. Bohîltea R, Turcan N, Ionescu C, Toader O, Nastasia S, Neculcea D, Movileanu I, Munteanu $\mathrm{O}$ and Cîrstoiu M: The incidence of prematurity and associated short-term complications in a multidisciplinary emergency hospital from Romania 5th Romanian Congress of the Romanian Society of Ultrasound in Obstetrics and Gynecology: 105-112, 2017

29. Gestational Hypertension and Preeclampsia: ACOG practice bulletin summary, number 222. Obstet Gynecol 135: 1492-1495, 2020.

30. Bohiltea RE, Zugravu CA, Nemescu D, Turcan N, Paulet FP, Gherghiceanu F, Ducu I and Cirstoiu MM: Impact of obesity on the prognosis of hypertensive disorders in pregnancy. Exp Ther Med 20: 2423-2428, 2020.
31. Gerhardt A, Scharf RE, Beckmann MW, Struve SP, Bender HG, Pillny M, Sandmann W and Zotz RB: Prothrombin and factor V mutations in women with a history of thrombosis during pregnancy and the puerperium. N Engl J Med 342: 374-380, 2000.

32. Benedetto C, Marozio L, Tavella AM, Salton L, Grivon S and Di Giampaolo F: Coagulation disorders in pregnancy: Acquired and inherited thrombophilias. Ann NY Acad Sci 1205: 106-117, 2010.

33. Van der Meer FJ, Koster T, Vandenbroucke JP, Briët E and Rosendaal FR: The leiden thrombophilia study (LETS). Thromb Haemost 78: 631-635, 1997.

34. Kocher O, Cirovic C, Malynn E, Rowland CM, Bare LA, Young BA, Henslee JG, Laffler TG, Huff JB, Kruskall MS, et al: Obstetric complications in patients with hereditary thrombophilia identified using the LCx microparticle enzyme immunoassay: A controlled study of 5,000 patients. Am J Clin Pathol 127: 68-75, 2007.

35. Turcan N, Bohîltea R, Neacsu A, Baros Al and Cîrstoiu MM: The role of anticoagulant therapy in the prevention of preeclampsia. Pharmacokinetic and pharmacodinamic mechanisms. Rev Chim 70: 1424-1428, 2019.

36. Rey E, Kahn SR, David M and Shrier I: Thrombophilic disorders and fetal loss: A meta-analysis. Lancet 361: 901-908, 2003.

37. Mogos M, Herghelegiu CG, Ioan RG, Cringu AI and Neacsu A: Determining an umbilical cord $\mathrm{pH}$ cutoff value for predicting neonatal morbidity related to intrapartum hypoxia. Rev Chim 70: 605-607, 2019.

38. Heit JA, Kobbervig CA, James HA, Petterson TM, Bailey KR and Melton LJ III: Trends in the incidence of venous thromboembolism during pregnancy or postpartum: A 30-year population-based study. Ann Intern Med 143: 697-706, 2005.

39. Bohiltea RE, Turcan G, Cirstoiu MM, Ionescu C, Nemescu D, Turcan N and Vladareanu R: Clinical implementation of ultrasound gynecological examination report (software REGU) Based on International Consensuses of Tumor Study Groups. 5th Romanian Congress of the Romanian Society of Ultrasound in Obstetrics and Gynecology: 99-104, 2017.

40. DeVore GR: The importance of the cerebroplacental ratio in the evaluation of fetal well-being in SGA and AGA fetuses. Am J Obstet Gynecol 213: 5-15, 2015.

41. Ionescu AC, Popescu I, Banacu M, Matei A, Bohîltea R and Dimitriu M: Is it possible to predict stillbirth in the third trimester? Filodiritto Editore-Proceedings. 5th Romanian Congress of the Romanian Society of Ultrasound in Obstetrics and Gynecology: 194-198, 2017.

42. Morris JM, Thompson K, Smithey J, Gaffney G, Cooke I, Chamberlain P, Hope P, Altman D and MacKenzie IZ: The usefulness of ultrasound assessment of amniotic fluid in predicting adverse outcome in prolonged pregnancy: A prospective blinded observational study. BJOG 110: 989-994, 2003.

43. Roqué H, Paidas MJ, Funai EF, Kuczynski E and Lockwood CJ: Maternal thrombophilias are not associated with early pregnancy loss. Thromb Haemost 91: 290-295, 2004.

44. Van Pampus MG,DekkerGA, WolfH,Huijgens PC,Koopman MM, von Blomberg BM and Büller HR: High prevalence of hemostatic abnormalities in women with a history of severe preeclampsia. Am J Obstetrics Gynecol 180: 1146-1150, 1999.

45. Hossain N, Shamsi T and Soomro N: Frequency of thrombophilia in patients with adverse pregnancy outcome. J Pak Med Assoc 55: 245-247, 2005.

46. Jivray S, Rai R, Underwood J and Regan L: Genetic thrombophilic mutations among couples with recurrent miscarriage. Hum Reprod 21: 1161-1165, 2006.

47. Alfirevic Z, Roberts D and Martlew V: How strong is the association between maternal thrombophilia and adverse pregnancy outcome? A systematic review. Eur J Obstet Gynecol Reprod Biol 101: 6-14, 2002.

48. Lin J and August P: Genetic thrombophilias and preeclampsia: A meta-analysis. Obstet Gynecol 105: 182-192, 2005.

49. Rey E, Garneau P, David M, Gauthier R, Leduc L, Michon N, Morin F, Demers C, Kahn SR, Magee LA and Rodger M: Dalteparin for the prevention of recurrence of placental-mediated complications of pregnancy in women without thrombophilia: A pilot randomized controlled trial. J Thromb Haemost 7: 58-64, 2009.

50. Mello G,Parretti E, Fatini C, Riviello C, Gensini F, Marchionni M, Scarselli GF, Gensini GF and Abbate R: Low-molecular-weight heparin lowers the recurrence rate of preeclampsia and restores the physiological vascular changes in angiotensin-converting enzyme DD women. Hypertension 45: 86-91, 2005. 
51. Bohîltea RE, Cîrstoiu MM, Ionescu CA, Niculescu-Mizil E, Vlădăreanu AM, Voican I, Dimitriu M and Turcan N: Primary myelofibrosis and pregnancy outcomes after low molecular-weight heparin administration: A case report and literature review. Medicine (Baltimore) 96: e8735, 2017.

52. Antovic A, Blombäck M, Bremme K and He S: The assay of overall haemostasis potential used to monitor the low molecular mass (weight) heparin, dalteparin, treatment in pregnant women with previous thromboembolism. Blood Coagul Fibrinolysis 13: 181-186, 2002.

53. Rodger MA, Gris JC, de Vries JIP, Martinelli I, Rey É, Schleussner E, Middeldorp S, Kaaja R, Langlois NJ, Ramsay T, et al: Low-Molecular-Weight heparin for placenta-mediated pregnancy complications study group. low-molecular-weight heparin and recurrent placenta-mediated pregnancy complications: A meta-analysis of individual patient data from randomised controlled trials. Lancet 388: 2629-2641, 2016.

54. RCOG (Royal College of Obstetricians and Gynecologysts). Thromboprophylaxis during pregnancy, labor and after vaginal delivery. RCOG Guideline No. 37, January 2004. Accessed November 2, 2020.

55. Gates S, Brocklehurst P and Davis LJ: Prophylaxis for venous thromboembolic disease in pregnancy and the early postnatal period. Cochrane Database Syst Rev 2002: CD001689, 2002.
56. Cardiovascular Disease Educational and Research Trust; Cyprus Cardiovascular Disease Educational and Research Trust; European Venous Forum; International Surgical Thrombosis Forum; International Union of Angiology; Union Internationale de Phlébologie: Prevention and treatment of venous thromboembolism. International Consensus Statement. Guidelines according to scientific evidence. Int Angiol 25: 101-161, 2006.

57. Royal College of Obstetricians and Gynaecologists (RCOG): Green-top guideline on reducing the risk of venous thromboembolism during pregnancy and the puerperium, 3rd edition, 2015. Accessed November 2, 2020.

58. Berghella V (ed): Maternal-Fetal Evidence Based Guidelines. 3rd edition. pp254-283, 2017

59. American College of Obstetricians and Gynecologists Women's Health Care Physicians: ACOG Practice Bulletin No. 138: Inherited thrombophilias in pregnancy. Obstet Gynecol 122: 706-717, 2013.

60. Robertson L, Wu O, Langhorne P, Twaddle S, Clark P, Lowe GD, Walker ID, Greaves M, Brenkel I, Rega L, et al: Thrombophilia in pregnancy: A systematic review. Br J Haematol 132: 171-196, 2006. 